Educação

Matemática Debate

licenciada sob Creative Commons

\section{cc) $(\$)$}

Josué Antunes de Macêdo Doutor em Ensino de Ciências e Matemática pela Universidade Cruzeiro do Sul (Unicsul). Professor do Instituto Federal de Educação, Ciência e Tecnologia do Norte de Minas Gerais (IFNMG), Minas Gerais, Brasil. Email: josueama@gmail.com

Lailson dos Reis Pereira Lopes

Doutorando em Educação Matemática pela Pontifícia Universidade Católica de São Paulo (PUC-SP). Professor da Universidade Estadual de Montes Claros (Unimontes), Minas Gerais, Brasil. E-mail:

lailson.lopespereira@yahoo.com.br

Laís de Souza Gusmão Licenciada em Matemática pelo Instituto Federal de Educação, Ciência e Tecnologia do Norte de Minas Gerais (IFNMG). Professora da Secretaria de Estado da Educação de Minas Gerais (SEE MG), Minas Gerais, Brasil. E-mail: laisgusma007@yahoo.com.b

Recebido em 31/01/2018 Aceito em 04/04/2018

\section{Resolução de problemas de otimização nas aulas de Matemática}

\section{Optimization problems resolution in Mathematics classes}

Josué Antunes de Macêdo

Lailson dos Reis Pereira Lopes

Laís de Souza Gusmão

\section{Resumo:}

Atualmente existem processos de otimização que contribuem com a vida de pessoas, como é o caso dos problemas resolvidos com a ajuda da Matemática. É a maneira técnica de se encontrar meios de minimizar tempo e, consequentemente, reduzir os custos de processos que se precisa realizar. A Matemática, em seu vasto campo de atuação, proporciona um arsenal de processos de otimização que enriquece e facilita o cotidiano. Em vista desta realidade, neste trabalho, apresentamos possíveis aplicações de alguns problemas de otimização, bem como mostramos a resolução de alguns problemas e discutimos a possibilidade da utilização da metodologia da resolução de problemas. Este trabalho permitiu o aprofundamento do conhecimento desse campo da Matemática, e suas contribuições em diversas áreas do conhecimento.

Palavras-chave: Otimização. Problemas. Resolução de problemas.

\section{Abstract:}

Currently there are optimization processes that contribute to the lives of people, as is the case of problems solved with the help of Mathematics. It is the technical way of finding ways to minimize time and, consequently, reduce the costs of processes that need to be done. Mathematics, in its vast field of action, provides an arsenal of optimization processes that enriches and facilitates daily life. In view of this reality, in this work, we present possible applications of some optimization problems, as well as show the resolution of some problems and discuss the possibility of using the problem solving methodology. This work allowed the deepening of the knowledge of this field of Mathematics, and its contributions in several areas of knowledge.

Keywords: Optimization. Problems. Problem solving. 


\section{Introdução}

Este trabalho apresenta alguns problemas de otimização e suas aplicações, bem como a possibilidade da utilização da metodologia da resolução de problemas em suas resoluções. Em muitas situações do cotidiano, depara-se com várias questões do tipo: Qual é a forma geométrica que um recipiente deve ter para comportar o maior volume possível? Ou ainda, qual é a maior área que se consegue cercar com uma quantidade conhecida de tela? A Matemática tem um ambiente reservado a dedicar-se a responder questões que se relacionam com o mundo da otimização.

A solução para uma questão de otimização é o ponto que representa os valores extremos de uma função, ou seja, o menor ou o maior valor que uma função pode admitir em um dado intervalo. Trata-se de questões comuns da vida cotidiana, e surgem quando se procura estabelecer o nível de produção mais econômico de uma indústria; o ponto da órbita de um cometa mais próximo da Terra; o consumo de despesas do dia a dia; a velocidade mínima necessária para que um foguete escape da atração gravitacional da Terra, dentre outros.

Geralmente os problemas de otimização são resolvidos com o uso do Cálculo Diferencial. No entanto, esses problemas ocorrem em situações corriqueiras ou mesmo em aplicações surgidas na educação básica, costumeiramente relacionados com as funções quadráticas, em que se pretende verificar os valores máximos ou mínimos, que se obtém por meio da determinação das coordenadas do vértice da parábola. As vezes, pode-se resolver problemas de otimização utilizando-se conceitos de geometria básica.

Os processos de otimização são aplicados frequentemente nas indústrias, quando se quer maximizar a produção, com redução de custos, por exemplo. Quando se quer produzir um veículo com maior espaço, utilizando-se uma quantidade menor de material; quando se deseja estabelecer rotas para caminhões de transportes de mercadorias, economizando assim tempo e combustível; nos projetos de espaços e prédios públicos capazes de acomodar com conforto uma quantidade máxima de pessoas, com o mínimo de custo possível.

Nesse sentido, neste trabalho apresentamos possíveis aplicações de alguns problemas de otimização e as contribuições da metodologia de resolução de problemas nas suas resoluções. O professor poderá utilizar-se dessa ferramenta para planejar boas aulas, utilizando-se exemplos práticos e do dia a dia, melhorando assim e tornando suas aulas mais problematizadoras de situações do interesse de seus alunos. 
A utilização da resolução de problemas por meio da otimização, nos diversos níveis de ensino, poderá aumentar o grau de motivação dos alunos para o estudo da Matemática, sendo possível também mostrar suas aplicações e importância de se estudar tal conteúdo.

Os problemas podem ser desenvolvidos com alunos do Ensino Médio, e trabalhados também na formação inicial de professores de Matemática. No segundo caso, é importante que sejam trabalhados os aspectos epistemológicos, metodológicos e didáticos do ensino e da aprendizagem que irão instrumentalizar o futuro professor para a prática docente.

Ao se tratar do assunto problemas matemáticos é difícil não mencionar George Polya. 0 autor propõe um esquema de como resolver um problema. As etapas descritas são as seguintes: compreensão do problema, estabelecimento de um plano, execução do plano e retrospecto (POLYA, 2006). O autor ressalta que não se deve eliminar nenhuma dessas fases. Cada momento tem sua relevância para o desenvolvimento do raciocínio.

O tema abordado se aproxima de estudos de autores que desenvolvem esquemas de como resolver problemas, uma questão que envolve técnicas da Matemática. Entre estes estudiosos, pode-se citar Rogawski (2009) e Stewart (2006, 2013).

O texto está estruturado da seguinte forma: inicialmente apresenta-se essa introdução, contendo um panorama geral do tema, com os objetivos a serem alcançados, justificativa do seu desenvolvimento e metodologia utilizada. A segunda seção trata do referencial teórico. Segue-se um roteiro de problemas na terceira seção. Na quarta seção apresentam-se as considerações finais.

\section{Referencial teórico}

A Matemática é uma ciência útil e necessária, que nos auxilia a compreender e a solucionar situações que exigem respostas e ou soluções exatas. O conhecimento matemático auxilia na aplicação de técnicas que permitem alcançar soluções da vida diária, progresso e desenvolvimento do mundo em si.

Segundo D’Ambrosio (2013, p. 113), "a matemática tem sido conceituada como a ciência dos números e das formas, das relações e das medidas, das inferências, e suas características apontam para precisão, rigor, exatidão".

Nos chama a atenção, a constatação feita por Moysés (2007), que a Matemática ensinada 
na sala de aula não vem correspondendo com as reais necessidades das pessoas em seu dia a dia. De acordo com esse autor, "o reconhecimento de que a matemática raramente é ensinada da forma como é praticada tem levado estudiosos a rever esse ensino" (MOYSÉS, 2007, p. 60).

Nesse sentido, D’Ambrosio (2017, p. 31), afirma que "interessa à criança, ao jovem e ao aprendiz em geral aquilo que tem apelo às suas percepções materiais e intelectuais mais imediatas". O referido autor considera que a abordagem matemática com vistas à realização de uma tarefa, é importante para motivar o aluno. Porém, é necessário também situações não imediatistas que funcionem como desafio intelectual para o educando, devendo o educador combinar os dois aspectos.

A Matemática é uma ciência presente em outras ciências, como a Física, a Química, a Biologia, entre outras. Pode ser encontrada numa composição de nota musical, na elaboração de um aplicativo computacional, na construção de um edifício, na administração de uma empresa ou de uma escola. Nesse sentido, Santos (2008) considera ser

\begin{abstract}
[...] necessário, porém, analisar esse fenômeno sobre outro ponto de vista. Por um lado, há um conjunto de atividades no dia a dia de cada um em que noções matemáticas saltam à vista e favorecem o seu reconhecimento como ferramenta necessária à compreensão do mundo. Por outro lado, há incontáveis atividades em que se pode até desconfiar da presença da matemática sem que seja percebida qual matemática está sendo utilizada e qual sua extensão. (SANTOS, 2008, p. 1)
\end{abstract}

Assim, percebe-se as contribuições dadas pela Matemática à sociedade, isto é, seu vasto campo de aplicabilidade, não apenas tecnológica, como também humana.

D'Ambrosio (2013) lista alguns motivos que justificam o ensino e aprendizagem de Matemática: "por ser útil como instrumentador para a vida; por ser útil como instrumentador para o trabalho; por ser parte de nossas raízes culturais; por ajudar a pensar com clareza e a raciocinar melhor; por sua beleza intrínseca como construção lógica e formal" (D’AMBRÓSIO 2013, p. 1619).

Nas justificativas apontadas pelo autor, verifica-se que quase todas remetem a situações do cotidiano, sejam elas relacionadas ao trabalho ou ao convívio social. Nessa mesma compreensão, reverbera o parágrafo segundo, do artigo primeiro, da Lei de Diretrizes e Bases da educação nacional (BRASIL, 1996): "a educação escolar deverá vincular-se ao mundo do trabalho e à prática social". Além do artigo 30: "O ensino será ministrado com base nos seguintes princípios", e do e inciso XI - vinculação entre a educação escolar, o trabalho e as práticas sociais. Apenas a última justificativa aponta para a formalidade matemática. 
Como já mencionado, nesse trabalho apresentamos alguns problemas clássicos de otimização e discutimos a possibilidade da utilização da metodologia da resolução de problemas na busca das soluções.

Segundo Macarini (2007), a resolução de problemas é apontada como uma tendência ou metodologia de ensino, em que o professor propõe aos alunos situações-problema, caracterizadas por investigações e exploração de novos conceitos. Também o aluno pode formular problemas para que seus colegas os resolvam, tornando a Matemática um conhecimento mais próximo do educando.

Echeverría e Pozo (1998, p.14) consideram que "ensinar a resolver problemas não consiste somente em dotar os alunos de habilidades e estratégias eficazes, mas também em criar neles o hábito e a atitude de enfrentar a aprendizagem como um problema para o qual deve ser encontrada uma resposta". Os autores salientam que o termo problema pode assumir diferentes significados dependendo do contexto, das características e das expectativas dos envolvidos.

Os problemas colocados em sala de aula pelos professores podem ser triviais para um grupo de alunos e para outro grupo, as soluções dos problemas responderiam apenas a situações de sala de aula, por não ter sentido no dia a dia de muitos deles. De acordo com Echeverría e Pozo (1998), não basta ensinar a resolver problema, mas ensinar o aluno a propor problemas para si próprios, que ele seja capaz de perceber na realidade cotidiana os problemas e buscar resolvêlos.

Parece-nos importante buscar diferenciar o que é um exercício e o que é um problema.

Segundo Echeverría e Pozo (1998), se a atividade indicada requer atitudes e a utilização de procedimentos automatizados, de imediato já se percebe como resolvê-lo se tornando uma prática contínua, tem-se neste caso, um exercício.

Nesse sentido, Silva (2016, p. 2) ressalta que muitas vezes o professor utiliza os vocábulos problemas e exercício como sinônimos, entretanto

[...] o exercício é uma atividade de treinamento (adestramento) no uso de alguma habilidade ou conhecimento matemático adquirido anteriormente pelo aluno, por exemplo, a aplicação de uma fórmula ou um algoritmo. Dessa forma, um exercício é uma mera aplicação de resultados teóricos, na maioria das vezes memorizados.

Na concepção de Onuchic (1999, p. 215), se entende por problema, "tudo aquilo que não se sabe fazer, mas que se está interessado em resolver". Na mesma perspectiva, Polya (2003, p. 
56), considera que, "ter um problema significa buscar conscientemente por alguma ação apropriada para atingir um objetivo claramente definido, mas não imediatamente atingível". Na concepção de Dante (1991, p. 9), "um problema é qualquer situação que exija o pensar do indivíduo para solucioná-la".

Verifica-se que as concepções dos autores convergem para a ideia de que problema é uma situação nova que exige a busca de uma solução, que envolve a definição de objetivos e 0 pensar.

Echeverría e Pozo (1998) chamam a atenção para o fato de que, uma atividade pode ser para um aluno um exercício e para outro, um problema. Isto, devido aos diferentes conhecimentos, expectativas e atitudes de cada um.

Onuchic e Allevato (2011) sugerem um roteiro de aula, que se inicia com a seleção dos problemas por parte do professor, visando a construção de novos conceitos, o que os autores chamam de problema gerador: Têm-se assim as etapas: "1. preparação do problema; 2. leitura individual; 3. leitura em conjunto; 4. resolução do problema; 5. observar e incentivar; 6. registro das resoluções na lousa; 7. plenária; 8. busca por consenso; 9. formalização do conteúdo" (ONUCHIC e ALLEVATO, p. 83-84).

Nessa proposta, pode-se perceber a importância do planejamento do professor para seleção dos problemas, de incentivador dos alunos e observador do desenvolvimento das atividades e das discussões em grupo; bem como, ao final, realizar formalização do conteúdo.

Quando se fala em ensino e aprendizagem, é impossível não relacionar a tríade, sujeito que ensina, sujeito que aprende e objeto da aprendizagem. Nas Orientações Curriculares para o Ensino Médio (BRASIL, 2006), são mencionadas duas correntes de ensino e aprendizagem, principalmente da Matemática: a primeira delas, utilizada com maior frequência, no ensino baseado na transmissão do conteúdo por parte do professor e na aprendizagem, sendo o aluno mero receptor. Nesse modelo, a vantagem é atingir um grande número de alunos, porém o seu êxito, requer alunos motivados e atentos aos ensinamentos do professor. Na realidade em que vivemos, não temos encontrado alunos com essa motivação.

Ainda de acordo com o referido documento, a segunda corrente, ainda pouco explorada, coloca o aluno no centro do processo de ensino e aprendizagem, como construtor do seu próprio conhecimento, e o professor como mediador desse processo. No primeiro caso, as aulas baseiamse na exposição do conteúdo, nos exemplos e nos exercícios de fixação. Já na segunda corrente, 
"tem-se o caminho inverso, ou seja, a aprendizagem de um novo conceito matemático dar-se-ia pela apresentação de uma situação problema ao aluno, ficando a formalização do conceito como a última etapa do processo de aprendizagem" (BRASIL, 2006, p. 81).

Na metodologia de ensino baseada na resolução de problema, o aluno deixa de ser mero receptor para se tornar construtor do seu conhecimento, a partir das discussões em grupo, do confronto de concepções, dos conhecimentos anteriores mobilizados. Nesse processo, 0 professor é o mediador, incentivador, orientador e responsável pela formalização dos conceitos.

Nos tópicos a seguir, serão tratados alguns problemas de otimização, evidenciando a importância do Cálculo Diferencial e Integral para o ramo da Matemática Aplicada.

\section{Alguns problemas de otimização}

De acordo com as Orientações Curriculares para o Ensino Médio (BRASIL, 2006, p. 72), o estudo das funções pode ser introduzido por meio de relações entre duas grandezas como, por exemplo, "idade e altura; área do círculo e raio; tempo e distância percorrida; tempo e crescimento populacional; tempo e amplitude de movimento de um pêndulo, entre outras". O professor deve instigar os alunos para apresentar outras situações envolvendo relações entre grandezas e representar o esboço gráfico, verificar o crescimento ou decrescimento entre as variáveis, além da representação algébrica.

Ainda de acordo com o referido documento, posteriormente o componente de estudo das funções deve contemplar as funções do tipo linear, quadrática e exponencial.

\footnotetext{
É recomendável que o aluno seja apresentado a diferentes modelos, tomados em diferentes áreas do conhecimento (queda livre de um corpo, movimento uniforme e uniformemente acelerado, crescimento de uma colônia de bactérias, quantidade de medicamento na corrente sanguínea, rendimentos financeiros, consumo doméstico de energia elétrica, etc.). (BRASIL, 2006, p. 72)
}

As Orientações Curriculares para o Ensino Médio (BRASIL, 2006) ressaltam ainda a importância de apresentação de situações de aplicação do conhecimento. Nesse sentido, buscouse atividades que permitem explorar e apresentar essas situações.

Neste trabalho são apresentados alguns problemas de otimização extraídos das obras de Rogawski (2009) e Stewart (2006; 2013). 


\section{Problema 1 - Área máxima de um retângulo}

(adaptado de Rogawski, 2009, p. 219)

Um pedaço de arame de comprimento $L$ é dobrado no formato de um retângulo, como é apresentado na figura abaixo. Quais dimensões dão o retângulo de área máxima?

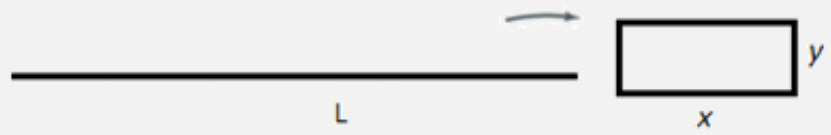

Se o retângulo tem lados de comprimento $x$ e $y$, sua área é $A=x y$. Como $A$ depende das duas variáveis $x$ e $y$, não se sabe como descobrir o máximo valor a ser obtido enquanto não for eliminada uma das variáveis. Isso pode ser realizado devido às variáveis estarem relacionadas: o perímetro do retângulo é $L$, logo $2 x+2 y=L$. Isso dá $y=\frac{L}{2}-x$ e, agora, pode-se reescrever a área como uma função somente de $x$ :

$$
A(x)=x\left(\frac{L}{2}-x\right)=\left(\frac{L}{2}\right) x-x^{2}
$$

Basta agora definir o intervalo que ocorre a otimização. Como os lados do retângulo não podem ter comprimentos negativos, têm-se que exigir ambos $x \geq 0$ e $\frac{L}{2}-x \geq 0$. Assim, $0 \leq x \leq \frac{L}{2}$ e o problema se restringe a descobrir o máximo de $A(x)$ no intervalo fechado $\left[0, \frac{L}{2}\right]$.

Resolvendo, ao derivar a equação (1), obtém-se $A^{\prime}(x)=\frac{L}{2}-2 x=0$, de onde $x=\frac{L}{4}$ é o ponto crítico. Resta calcular os valores da área em função de $x, A(x)$ nas extremidades e no ponto crítico.

Extremidades: $A(0)=0$

$$
A\left(\frac{L}{2}\right)=\frac{L}{2}\left(\frac{L}{2}-\frac{L}{2}\right)=0
$$

Ponto crítico:

$$
A\left(\frac{L}{4}\right)=\left(\frac{L}{4}\right)\left(\frac{L}{2}-\frac{L}{4}\right)=\frac{L^{2}}{16}
$$

Isso mostra que a maior área ocorre $\operatorname{com} x=\frac{L}{4}$. O valor para $y=\frac{L}{2}-x$ é

$$
y=\frac{L}{2}-x=\frac{L}{2}-\frac{L}{4}=\frac{L}{4}
$$


Assim, o retângulo de área máxima é o quadrado de lados $x=y=\frac{L}{4}$.

\section{Problema 2 - Minimização de tempo de viagem (adaptado de Rogawski, 2009, p. 219)}

O vaqueiro Chico deseja arquitetar uma trilha de seu sítio até a estrada de maneira que possa chegar à cidade no menor tempo possível (figura abaixo). A distância perpendicular do sítio à estrada é de $4 \mathrm{~km}$ e a cidade está a $9 \mathrm{~km}$ adiante na estrada. Em que ponto Chico deveria ligar a trilha à estrada se a velocidade máxima que ele consegue atingir na trilha é de $20 \mathrm{~km} / \mathrm{h}$ e na estrada de $55 \mathrm{~km} / \mathrm{h}$ ?

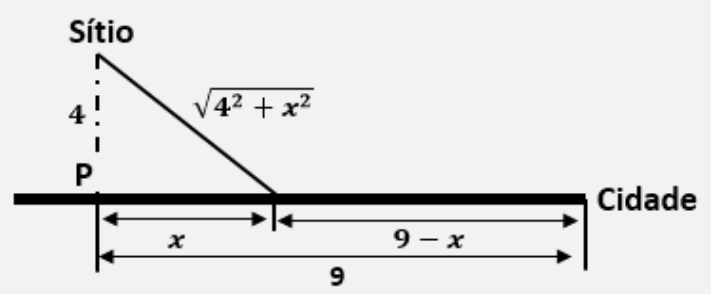

Esse problema requer mais cuidado para resolver em comparação ao antecedente, logo deve-se analisá-lo em três situações. Essas situações podem ser seguidas para resolver outros problemas de otimização.

Passo 1 - Escolher variáveis. É necessário decidir onde ligar a trilha à estrada. Seja, pois, $P$ o ponto da estrada mais perto do rancho e $x$ a distância de $P$ ao ponto em que a trilha se junta à estrada.

Passo 2 - Encontrar a função e o intervalo. Como deseja-se minimizar o tempo de viagem, calcula-se o tempo de viagem $T(x)$ como função de $x$. Pelo Teorema de Pitágoras, o comprimento da trilha é $\sqrt{4^{2}+x^{2}} \mathrm{~km}$. Quanto tempo leva para percorrer a trilha a $20 \mathrm{~km} / \mathrm{h}$ ? Deve-se lembrar que, à velocidade constante $v$, a distância percorrida é de $d=v t$. Portanto, o tempo necessário para percorrer uma distância $d$ é $t=\frac{d}{v}$. Aplicando isso a $v=20 \mathrm{~km} / \mathrm{h}$, é possível perceber que leva-se $\frac{\sqrt{4^{2}+x^{2}}}{20}$ horas para percorrer a trilha.

A parte da estrada tem comprimento $(9-x) \mathrm{km}$. A uma velocidade de $55 \mathrm{~km} / \mathrm{h}$, leva-se $\frac{9-x}{55}$ horas para percorrer a estrada. $O$ total de horas de viagem é:

$$
\mathrm{T}(x)=\frac{\sqrt{16+x^{2}}}{20}+\frac{9-x}{55}
$$


Como 0 atalho se junta à estrada em algum ponto entre $\mathrm{P}$ e a cidade, tem-se $0 \leq x \leq 9$. Assim sendo, o problema é descobrir o mínimo de $T(x)$ em $[0,9]$.

Passo 3 - Otimizar a função. Derivando a equação (5) e fazendo $T^{\prime}(x)=0$ para se encontrar os pontos críticos:

$$
\begin{gathered}
\mathrm{T}^{\prime}(x)=\frac{x}{20 \sqrt{16+x^{2}}}-\frac{1}{55}=0 \\
55 x=20 \sqrt{16+x^{2}} \\
11 x=4 \sqrt{16+x^{2}} \\
121 x^{2}=16\left(16+x^{2}\right)
\end{gathered}
$$

Como interessa apenas o valor de $x$ positivo, tem-se, $105 x^{2}=16^{2}$ ou $x=\frac{16}{\sqrt{105}}$, de onde $x \approx 1,56 \mathrm{~km}$. Para encontrar o valor mínimo de $T(x)$, calcula-se $T(x)$ no ponto crítico $\mathrm{e}$ nas extremidades de $[0,9]: T(0) \approx 0,36 h ; T(1,56) \approx 0,35 h$; e $T(9) \approx 0,49 h$.

É possível, então, concluir que o tempo de viagem é minimizado se 0 atalho for ligado à estrada a uma distância de $x \approx 1,56 \mathrm{~km}$ de $P$.

O Cálculo é largamente utilizado para definir problemas de otimização que emergem em tomadas de decisão de negócios.

O exemplo seguinte é adaptado de uma análise da produção de milho no estado norteamericano do Kansas, feita em 1957 pelo economista norte-americano Earl Heady.

\section{Problema 3 - Maximizando a produção de milho (adaptado de Rogawski, 2009, p. 219)}

As experiências mostram que se um fertilizante constituído de $N$ quilogramas $(\mathrm{kg})$ de nitrogênio e $P \mathrm{~kg}$ de fosfato for utilizado num hectare de plantio em uma determinada região, então, a produção de milho é dada por $B=8+0,3 \sqrt{N P}$ unidades de massa por hectare. Suponha que o nitrogênio custe $\$ 25$ centavos $/ \mathrm{kg}$ e o fosfato custe $\$ 20$ centavos $/ \mathrm{kg}$. Se um agricultor pretende gastar 30 dólares com fertilizante por hectare, qual é a combinação de nitrogênio e fosfato que dá a produção máxima de milho?

A expressão para a produção $B$ depende das duas variáveis $N$ e $P$, portanto deve-se eliminar uma das variáveis. $O$ agricultor gastará 30 dólares por hectare, logo, tem-se a equação de vínculo: $0,25 N+0,2 P=30$ ou $P=150-1,25 N$. 
Substituindo na expressão de $B$, obtém-se uma função só de $N$ :

$$
B(N)=8+0,3 \sqrt{N(150-1,25 N)}
$$

Ambos $\mathrm{N}$ e $\mathrm{P}$ devem ser não-negativos. Como $P=150-1,25 \mathrm{~N} \geq 0$, é preciso que $0 \leq N \leq 120$. Em outras palavras, $\mathrm{B}(\mathrm{N})$ deve ser otimizado em $[0,120]$. Para encontrar os pontos críticos de $B(N)$, iguala-se a derivada a zero:

$$
\frac{d B}{d N}=\frac{0,3(150-2,5 N)}{2 \sqrt{N(150-1,25 N)}}=0
$$

Esse quociente é nulo se o numerador for zero, isto é $N=60$.

A derivada não está definida em $N=0$ e $N=120$, portanto esses pontos também são críticos (que casualmente são as extremidades). Calcula-se $B(N)$ nos pontos críticos: $B(0)=8 ; B(60)=8+0,3 \sqrt{60(150-1,25.60)} \approx 28 ;$ e $B(120)=8$.

O máximo ocorre em $N=60$. Pela equação de vínculo, $P=150-1,25(60)=75$. Portanto, a combinação ótima é $N=60 ; P=75$, isto é, para obter uma produção máxima de milho nas condições apresentadas, o produtor deverá utilizar um fertilizante com a combinação de $60 \mathrm{~kg}$ de nitrogênio e $60 \mathrm{~kg}$ de potássio.

\section{Problema 4 - Minimização de tempo de viagem (adaptado de Stewart, 2013, p. 297)}

Um homem lança seu bote em um ponto $A$ na margem de um rio reto, com uma largura de $3 \mathrm{~km}$, e deseja atingir tão rápido quanto possível um ponto $B$ na outra margem, $8 \mathrm{~km}$ rio abaixo (figura ao lado). Ele pode dirigir seu barco diretamente para 0 ponto $C$ e então seguir andando para $B$, ou rumar diretamente para $B$, ou remar para algum ponto $D$ entre $C$ e $B$ e então andar até $B$. Se ele pode remar a $6 \mathrm{~km} / \mathrm{h}$ e andar a $8 \mathrm{~km} / \mathrm{h}$, onde ele deveria aportar para atingir $B$ o mais rápido possível? (Supondo-se que a velocidade da água seja desprezível comparada com a velocidade na qual o homem rema.)

Chamando de $x$ a distância de $C$ a $D$, então a distância a ser percorrida a pé será $|D-B|=8-x$, e o Teorema de Pitágoras dará a distância remada como $|A D|=\sqrt{x^{2}+3^{2}}$. Usando a equação 


$$
\text { Tempo }=\frac{\text { distância }}{\text { velocidade }}
$$

Então, o tempo gasto remando é $\frac{\sqrt{x^{2}+9}}{6}$ horas, enquanto o tempo gasto andando é $\frac{8-x}{8}$ horas. Assim, o tempo total $T$ como uma função de $x$ é

$$
T(x)=\frac{\sqrt{x^{2}+9}}{6}+\frac{8-x}{8}
$$

Sendo o tempo positivo, o interesse passa a ser 0 intervalo $x \in[0,8]$. Note que, se $x=0$, ele rema para $C$, e se $x=8$, ele rema diretamente para $B$. A derivada de $T$ é

$$
T^{\prime}(x)=\frac{x}{6 \sqrt{x^{2}+9}}-\frac{1}{8}
$$

Assim, usando o fato de que $x \geq 0$, tem-se

$$
\begin{aligned}
T^{\prime}(x)=0 & \leftrightarrow \frac{x}{6 \sqrt{x^{2}+9}}=\frac{1}{8} \quad \leftrightarrow 4 x=3 \sqrt{x^{2}+9} \\
& \leftrightarrow 16 x^{2}=9\left(x^{2}+9\right) \quad \leftrightarrow 7 x^{2}=81 \\
& \leftrightarrow x=\frac{9}{\sqrt{7}}
\end{aligned}
$$

O único número crítico é $x=\frac{9}{\sqrt{7}}$. Para ver se o mínimo ocorre nesse número crítico ou nos extremos do domínio $[0,8]$, calcula-se $T$ em todos os três pontos: $T(0)=1,5$; $T\left(\frac{9}{\sqrt{7}}\right)=1+\frac{\sqrt{7}}{8} \approx 1,33$ e $T(8)=\frac{\sqrt{73}}{6} \approx 1,42$.

Uma vez que o menor desses valores de Tocorre quando $x=\frac{9}{\sqrt{7}}, 0$ valor mínimo absoluto de $T$ deve ocorrer lá. Dessa forma, um homem deve aportar o bote no ponto $\frac{9}{\sqrt{7}} \mathrm{~km}(\approx 3,4 \mathrm{~km})$ rio abaixo a partir do início. 


\section{Problema 5 - Minimizando o custo para produção de uma lata \\ (adaptado de Stewart, 2013, p. 295)}

Uma lata cilíndrica é feita para receber um litro de óleo como se pode ver na figura abaixo.

Encontre as dimensões que minimizarão o custo do metal para produzir a lata.

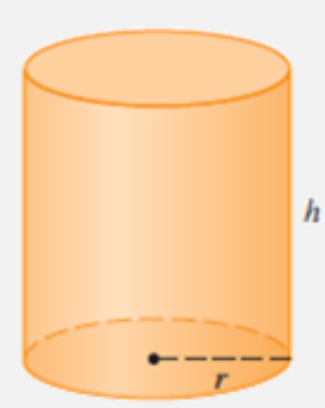

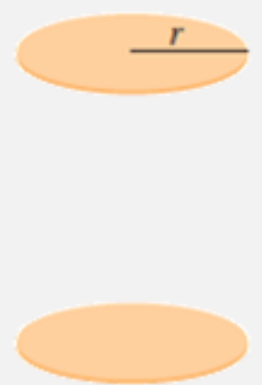

Área $2\left(\pi r^{2}\right)$

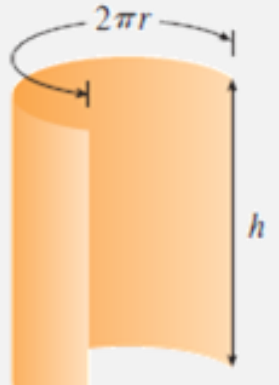

Área $(2 \pi r) h$

A fim de diminuir ao mínimo possível o custo do metal, deve-se minimizar a área da superfície total do cilindro. Logo a área da superfície é

$$
A=2 \pi r^{2}+2 \pi r h
$$

Utilizando-se o fato de que o volume (V) é dado como um litro, que é igual a $1000 \mathrm{~cm}^{3}$, torna-se possível eliminar $h$. Logo, $V=\pi r^{2} h=1000$, o que fornece $h=\frac{1000}{\pi r^{2}}$. Substituindo na expressão para a área $(\mathrm{A})$, tem-se $A=2 \pi r^{2}+2 \pi r\left(\frac{1000}{\pi r^{2}}\right)=2 \pi r^{2}+\frac{2000}{r}$.

Portanto, a função que se deseja minimizar é

$$
A(r)=2 \pi r^{2}+\frac{2000}{r} ; r>0
$$

Para encontrar os números críticos deve-se determinar a derivada de $A(r)$ :

$$
A^{\prime}(r)=4 \pi r-\frac{2000}{r^{2}}=\frac{4\left(\pi r^{3}-500\right)}{r^{2}}
$$

Então $A^{\prime}(r)=0$ quando $\pi r^{3}=500$; logo o número crítico é $r=\sqrt[3]{\frac{500}{\pi}}$. Uma vez que o raio $r$ deve estar no intervalo $r \in(0, \infty)$, pode-se observar que $A^{\prime}(r)<0$ para $r<\sqrt[3]{\frac{500}{\pi}}$ e $A^{\prime}(r)>0$ para $r>\sqrt[3]{\frac{500}{\pi}}$. portanto, $A$ está decrescendo para todo $r$ à esquerda do número crítico e crescendo para todo $r$ à direita. Assim $r=\sqrt[3]{\frac{500}{\pi}}$ deve originar um mínimo absoluto. 0 
valor de h correspondente a $r=\sqrt[3]{\frac{500}{\pi}}$ é:

$$
\begin{aligned}
h=\frac{1000}{\pi r^{2}} & =\frac{1000}{\pi\left(\frac{500}{\pi}\right)^{\frac{2}{3}}}=\sqrt[3]{\frac{100^{3}}{\pi^{3}} \times \frac{\pi^{2}}{500^{2}}}=\sqrt[3]{\frac{(500 \times 2)^{3}}{500^{2} \pi}} \\
h & =\sqrt[3]{\frac{500^{2} \times 500 \times 2^{3}}{500^{2} \pi}}=2 \sqrt[3]{\frac{500}{\pi}}=2 r
\end{aligned}
$$

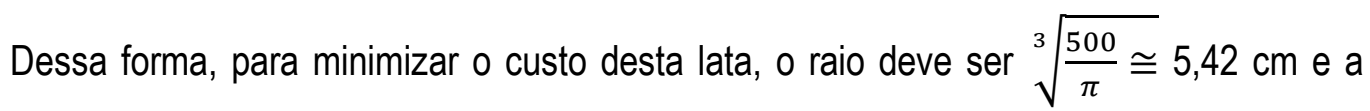
altura, igual a duas vezes o raio, isto é aproximadamente $10,84 \mathrm{~cm}$.

\section{Considerações}

De acordo com a discussão feita e apresentação de alguns problemas, foi possível conhecer possíveis aplicações de problemas de otimização. Esses problemas possuem um vasto emprego dentro do campo da Matemática, nas Ciências e Engenharia, e em diversos setores da vida humana, pessoal e social.

A vida social se desenvolveu e vem se desenvolvendo a cada dia com a interferência e influência da Matemática, em todos os aspectos de todos os outros saberes que ela alcança.

A realização deste trabalho promove ainda mais o conhecimento acadêmico acerca da efetividade da Matemática no cotidiano, associando suas metodologias de cálculos e técnicas às atividades e necessidades da vida humana.

O presente trabalho permitiu um novo olhar, uma nova perspectiva acerca da aplicabilidade, que é pouco aprofundada no ensino de Matemática, pois é interessante que as aplicações sejam discutidas com maior ênfase.

Na resolução dos problemas propostos por Rogawski (2009) e Stewart (2013), percebese as etapas da resolução de problemas propostas por Polya (2006), que são: compreensão do problema, estabelecimento de um plano, execução do plano e retrospecto.

Lembrando que de acordo com Echeverría e Pozo (1998), para um aluno, a atividade pode ser um problema, enquanto para outro, apenas um exercício, em virtude dos diferentes conhecimentos, perspectivas e costumes. 0 problema 1 , apresenta uma situação que talvez faça 
mais sentido para um aluno que pretende estudar Engenharia e se dedicar ao cálculo estrutural. O problema 2, pode ser um problema para um aluno que se dedicará a Engenharia de Tráfego, por exemplo. 0 problema 3, para um futuro engenheiro agrônomo. Ressalta-se que por esse motivo, o professor terá vários desafios, conforme destacado por Carvalho e Gil-Perez (2011), dentre eles

[...] estar preparado para situações inesperadas, o que requer domínio amplo do conteúdo. Ter conhecimento dos problemas que levaram a construção do conhecimento em determinada área da matemática, ou seja, ter conhecimento das pesquisas em educação matemática. Estar sempre em busca de novos conhecimentos, atualizado quanto aos assuntos matemáticos atuais. (CARVALHO e GIL-PEREZ, 2011, p. 80)

Pode-se utilizar o presente estudo como sugestão para trabalhos futuros, haja vista que 0 presente tema é precursor para o desenvolvimento de problemas relacionados a outras áreas específicas, servindo de material de estudo. Pode possibilitar ainda reflexões a respeito da exploração dos conteúdos matemáticos da Educação Básica, na formação inicial do futuro professor de Matemática.

\section{Referências}

BRASIL. Lei ñ. 9.394, de 20 de dezembro de 1996. Estabelece as diretrizes e bases da educação nacional. Brasília: Diário Oficial da União, 23 dez. 1996.

BRASIL. Ministério da Educação. Secretaria de Educação Básica. Orientações Curriculares para o Ensino Médio: Ciências da Natureza, Matemática e suas Tecnologias. v. 2. Brasília: MEC / SEF, 2006.

CARVALHO, Ana Maria Pessoa de; GIL-PÉREZ, Daniel. Formação de professores de ciências: tendências e inovações. 10. ed. São Paulo (SP): Cortez Editora, 2011.

D'AMBROSIO, Ubiratan. Etnomatemática: elo entre as tradições e a modernidade. 5. ed. Belo Horizonte: Autêntica Editora, 2013.

D'AMBROSIO, Ubiratan. Educação Matemática: da teoria à prática. 23 ed. Campinas: Papirus Editora, 2017.

DANTE, Luiz Roberto. Didática da resolução de problemas de matemática. 3. ed. São Paulo: Ática, 1991.

ECHEVERRÍA, Maria del Puy Pérez; POZO, Juan Ignacio. Aprender a resolver problemas e resolver problemas para aprender. In: POZO, Juan lgnacio (Org.). Solução de problemas: aprender a resolver, resolver para aprender. Porto Alegre: Artmed, 1998. p. 13-42. 
MACARINI, Adriana Rodrigues Luz. A Matemática nos anos iniciais do ensino fundamental: as estratégias de ensino como potencialidades da aprendizagem. 2007. 117f. Dissertação (Mestrado em Educação) - Universidade Vale do Itajaí. Itajaí.

MOYSÉS, Lúcia. Aplicações de Vygotsky à Educação Matemática. 8. ed. Campinas: Papirus, 2007.

ONUCHIC, Lourdes de la Rosa. Ensino-aprendizagem de Matemática através da resolução de problemas. In: BICUDO, Maria Aparecida Viggiani (Org.). Pesquisa em Educação Matemática: concepções e perspectivas. São Paulo: EdUNESP, 1999, 199-218.

ONUCHIC, Lourdes de la Rosa; ALLEVATO, Norma Suely Gomes. Pesquisa em resolução de problemas: caminhos, avanços e novas perspectivas. Bolema, Rio Claro, v. 5, n. 41, dez. 2011.

POLYA, George. Sobre a resolução de problemas de Matemática na high school In: KRULIK, Stephen; REYS, Robert E. (Org.). A resolução de problemas na matemática escolar. Tradução de Hygino Hugueros Domingues e Olga Corbo. 1 ed. São Paulo: Atual, 2003.

POLYA, George. A arte de resolver problemas: um novo aspecto do método matemático. Tradução de Heitor Lisboa de Araújo. 1 ed. 2 reimp. Rio de Janeiro: Interciência, 2006.

ROGAWSKI, Jon. Cálculo. v. 1. São Paulo: Artmed/Bookman, 2009.

SANTOS, Vinício de Macedo. A matemática escolar, o aluno e o professor: paradoxos aparentes e polarizações em discussão. Cadernos Cedes, Campinas, v. 28, n. 74, p. 25-38, jan./abr. 2008. DOI: 10.1590/S0101-32622008000100003.

SILVA, Valquírio Firmino. A resolução de problemas: concepções evidenciadas na prática e no discurso de professores de Matemática do ensino fundamental. In. X SIMPÓSIO LINGUAGENS E IDENTIDADES DA/NA AMAZÔNIA SUL-OCIDENTAL, 2016, Rio Branco. Anais do X SLIASO, Rio Branco: UFAC, 2016, p. 1-15.

STEWART, JAMES. Cálculo. v. 1. São Paulo: Pioneira Thomsom Learning, 2006.

STEWART, JAMES. Cálculo. v. 1. São Paulo: Pioneira Thomsom Learning, 2013. 